\title{
ARE DENTAL MEASUREMENTS TAKEN ON PLASTER CASTS COMPARABLE TO THOSE TAKEN FROM CBCT IMAGES AND LASER SCANNED SURFACES?

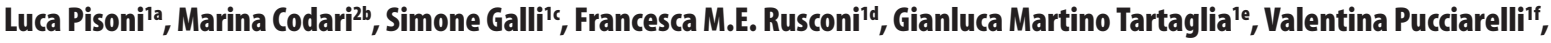 Chiarella Sforza' ${ }^{1 *}$
}

'LAFAS, Laboratory of Functional Anatomy of the Stomatognathic System, Department of Biomedical Sciences for Health, University of Milan, Milan, Italy

2Unit of Radiology, IRCCS Policlinico San Donato, Via Morandi 30, San Donato Milanese, 20097 Milan, Italy.

\author{
a,eDDS, PhD \\ ${ }^{\mathrm{D} M S B E}, \mathrm{PhD}$ \\ 'CDT \\ dDDS \\ 'MBiothec, PhD \\ ${ }^{9} \mathrm{MD}, \mathrm{PhD}$, Head
}

Introduction: Intraoral scanning techniques, laser scans and cone-beam computed tomography $(\mathrm{CBCT})$ are becoming widely diffused in dental practice. These instruments can replace dental plaster casts with digital models; recent investigations have found that measurements taken on digital models do not differ clinically from those obtained on CBCT scans and physical models, but only intra-examiner reliability has been assessed. In the current study we tested both intra- and inter-examiner variations, together with intertechniques reliability.

Methodology: Data from six adult subjects were retrospectively obtained. Twelve dental distances were measured on dental plaster casts using a digital calliper; on digital 3D CBCT images using inVivoDental software (Anatomage, San Jose, CA); and on laser scanned surfaces using Mirror Vectra Software (Canfield Scientific, Fairfield, NJ). Two different operators performed all measurements twice. Bland-Altman analysis, Kruskal-Wallis and Wilcoxon tests were used for comparisons.

Results: The intra- and inter-operator biases range was $0-0.34 \mathrm{~mm}$. The reproducibility range was $72-99 \%$. The three different techniques gave very similar measurements, with biases between $\pm 0.1 \mathrm{~mm}$. Reproducibility ranged between 90 and $100 \%$; the best reproducibility coefficients were found between plaster and digital casts, and only three differences were larger than $0.5 \mathrm{~mm}$. Calliper measurements slightly overestimated digital casts values. Only the mesiodistal distance of tooth $24(p=0.002)$ was significantly different among techniques. Conclusion: Measurements on digital dental models and CBCT reconstructions of the dental arches seem clinically reliable as direct calliper measurements. The inter- and intra-operator reliabilities were acceptable, some more care may be needed for CBCT measurements.

Keywords: teeth, laser scan, cone beam computerised tomography.

\begin{tabular}{l} 
OPEN ACCESS This is an \\
OPen Access article under the CC \\
BY-NC 4.0 license. \\
Citation: Pisoni L, Codari M, Gallis, \\
Rusconi FME, Tartaglia GM, Pucciarelli \\
V, Sforza C. Are dental measurements \\
taken on plaster casts comparable to \\
those taken from CBCT images and \\
laser scanned surfaces? Stoma Edu J. \\
2018; $5(1): 38-42$. \\
Academic Editor: Lidia Boboc, DDS, \\
PhD, Associate Professor, "Carol Davila" \\
University of Medicine and Pharmacy \\
Bucharest, Romania \\
Received: December 23, 2017 \\
Revised: February 09, 2018 \\
Acccepted: March 01, 2018 \\
Published: March 03, 2018 \\
*Corresponding author: Professor \\
Chiarella Sforza, MD, PhD, Head \\
Department of Biomedical Sciences \\
for Health, University of Milan, Milan, \\
Italyvia Mangiagalli31, I-20133 Milano, \\
Italy Tel: +39 - 02 503 15385, Fax: \\
+39-02 503 15387, e-mail: chiarella. \\
sforza@unimi.it \\
Copyright: $\odot$ 2018 the Editorial Coun- \\
cil for the Stomatology Edu Journal. \\
\hline
\end{tabular}

\section{Introduction}

New technologies like scanning techniques, conebeam computerised tomography (CBCT) and three dimensional imaging are becoming more and more used in all branches of dental practice (conservative, prosthodontics, surgery and orthodontics). Among the other applications, these devices can replace dental plaster casts with digital models possessing several advantages: easy storage, no necessary physical space, no damages during handling, and easy data share with other professionals [1-9].

$\mathrm{CBCT}$, in particular, gives a $3 \mathrm{D}$ representation of the cranio-facial and dental structures and has already several indications in clinical routine: oral and maxillofacial surgery (orthognathic surgery, treatment of traumas and malignancies, nerve tracing in cases of third molar extraction and implant placement), endodontics (root fracture detection), orthodontics (diagnosis and treatment planning) $[6,10-15]$. In this last field, several studies have successfully compared the accuracy of craniofacial measurements taken using landmarks identified on CBCT scans with those taken directly on skulls with conventional digital callipers [16, 17].

Safety, accuracy and reliability of measurements taken with new instruments must be evaluated and compared with those obtained with traditional methods also for dental landmarks: data obtained from both the digital and traditional plaster casts models must match in order to allow using the new technologies in clinical practice $[2,8,18]$.

In general, recent investigations found that measurements taken on digital models do not differ clinically from those obtained on CBCT scans and physical models $[4,5]$. Unfortunately, while reporting intra-examiner reliability, no inter-examiner variations were presented [6-8]. Indeed, the assessment of interoperator variations seems to be of relevance in the current scenario where dental technicians often work in centralised locations at distance from clinical offices, and several of them may be involved in the evaluation of the same dental reproductions.

In the current study, we compared measurements taken on digital models obtained from CBCT images and laser scanned surfaces with direct measurements 
obtained on dental plaster casts. Both intra- and interoperator reliabilities were assessed.

\section{Material and methods}

Data from six adult Caucasian subjects with full dentition, no implant surgery, dental fillings, prostheses or caries that could affect the morphology of teeth were obtained. The absence of implants and metal fillings was selected as inclusion criterion to reduce the presence of metal artefacts that can alter the measurement process.

All patients were retrospectively selected from a clinical database and underwent CBCT examination for clinical reasons uncorrelated with this study. Their plaster casts poured from alginate impressions, cast in gypsum and conventionally trimmed, were collected as well. They reproduced the full arches with no surface damage. The casts were imaged by a laser scan (iSeries, Dental Wings, Montreal, Canada), and their 3D digital models obtained [1]. The work described was carried out in accordance with The Code of Ethics of the World Medical Association (Declaration of Helsinki). Informed consent was obtained from all patients, and their privacy rights observed. Considering the retrospective nature of the study, no ethical approval was required. No clinical information was retrieved from the database.

Twelve dental distances (Fig. 1) were measured on dental plaster casts using a digital calliper; on digital 3D CBCT images using inVivoDental software (Anatomage, San Jose, CA); and on laser scanned surfaces using Mirror ${ }^{\circledR}$ Vectra Software (Canfield Scientific, Fairfield, NJ).

Two different operators performed all measurements twice. A previous calibration session was performed: each operator made the whole set of measurements on a dental plaster cast and on its digital reproduction, as well as on the CBCT images of a patient not included in the study. The results were discussed until a consensus about landmark location was obtained.

Intra- and inter-operator reliability was assessed by Bland-Altman analysis, and for each comparison both the reproducibility coefficient and the bias (difference between measurements divided by the mean value) were calculated $[7,18]$.

The mean values were computed separately for tooth and measurement (mesiodistal and vestibulopalatal or vestibulolingual crown diameters). The three different techniques were compared by Bland-Altman analysis and Kruskal-Wallis test, with the Wilcoxon test for posthoc comparisons.

For all tests, the statistical significance level was set to $\mathrm{p}<0.01$, with the Bonferroni correction for post-hoc comparisons.

\section{Results}

The intra- and inter-operator biases ranged between 0 and $0.34 \mathrm{~mm}$, and only $3 / 72$ biases were equal to larger than $|0.3| \mathrm{mm}$ (Table 1). These biases were observed for the vestibulopalatal diameters of teeth 24 and 26 (intraoperator analysis), and the vestibulopalatal diameter of tooth 26 (inter-operator analysis). Reproducibility ranged between 72 and $99 \%$, the worst coefficients were found for CBCT measurements (18/24 were lower than $90 \%)$,
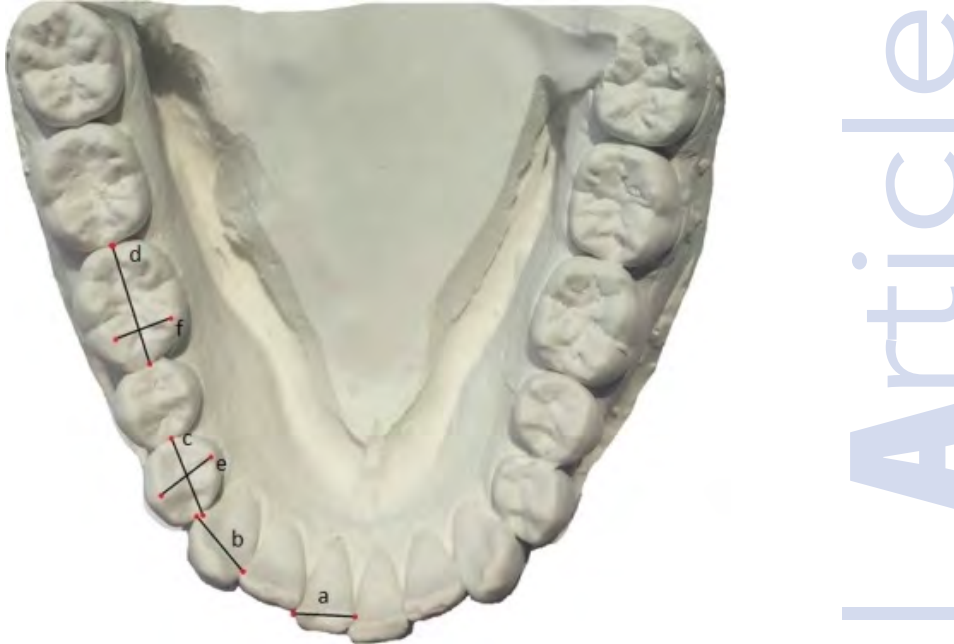

Figure 1. Dental crown distances chosen for the study in the right side mandibular arch. The corresponding distances were selected also in the left side maxillary arch: a) Mesiodistal distance of tooth 41; b) Mesiodistal distance of tooth 43; c) Mesiodistal distance of tooth 44; d) Mesiodistal distance of tooth $46 ; \mathrm{e}$ ) Distance from vestibular to lingual cusp of tooth 44; f) Distance from mesial-vestibular to mesial-lingual cusp of tooth 46.

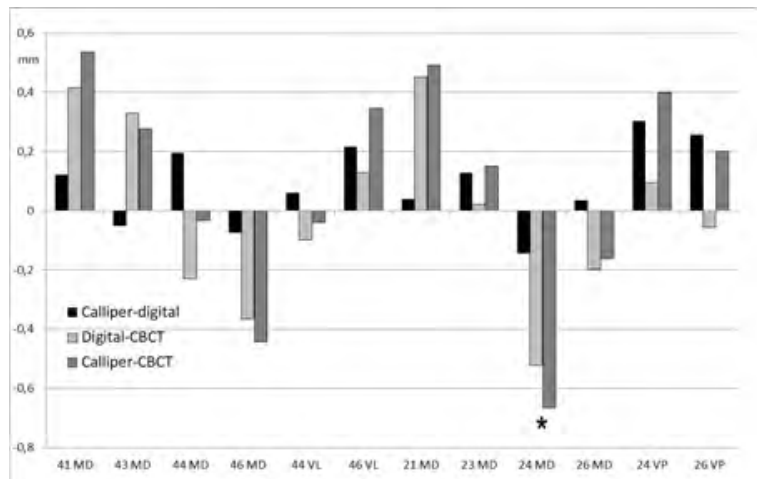

Figure 2. Mean differences between measurement methods. MD: Mesiodistal distance; VL or VP: vestibulolingual or vestibulopalatal distance. * $\mathrm{P}=0.002$, Kruskal-Wallis test

the best for plaster casts (all larger than 93\%). The intraand inter-operator reliabilities were comparable.

The three different techniques gave very similar measurements, with biases smaller than \pm 0.1 $\mathrm{mm}$, except the calliper-CBCT comparisons of the mesiodistal diameters of teeth 41 and 24 (Table 2). Reproducibility ranged between 90 and 100\%; the comparisons between plaster and digital casts had the best reproducibility coefficients (all larger than 97\%).

The mean differences ( \pm 1 SD) for calliper-digital, digital-CBCT and calliper-CBCT measurements were respectively $0.09 \pm 0.14,0 \pm 0.3,0.09 \pm 0.37 \mathrm{~mm}$ (Fig. 2).

Only three differences were larger than $0.5 \mathrm{~mm}$, which represents the threshold for clinical acceptability [7, 18]: calliper-CBCT for teeth 41 and 24, and digital-CBCT for tooth 24 (all mesiodistal crown diameter). Calliper measurements slightly overestimated digital cast values, while the other differences were more scattered. Only the mesiodistal distance of tooth 24 (KruskalWallis test, $p=0.002$ ) was significantly different among techniques (Table 3).

\section{Discussion}

In the present investigation, we compared dental 
Table 1. Intra- and inter-operator repeatability (Bland-Altman analysis).

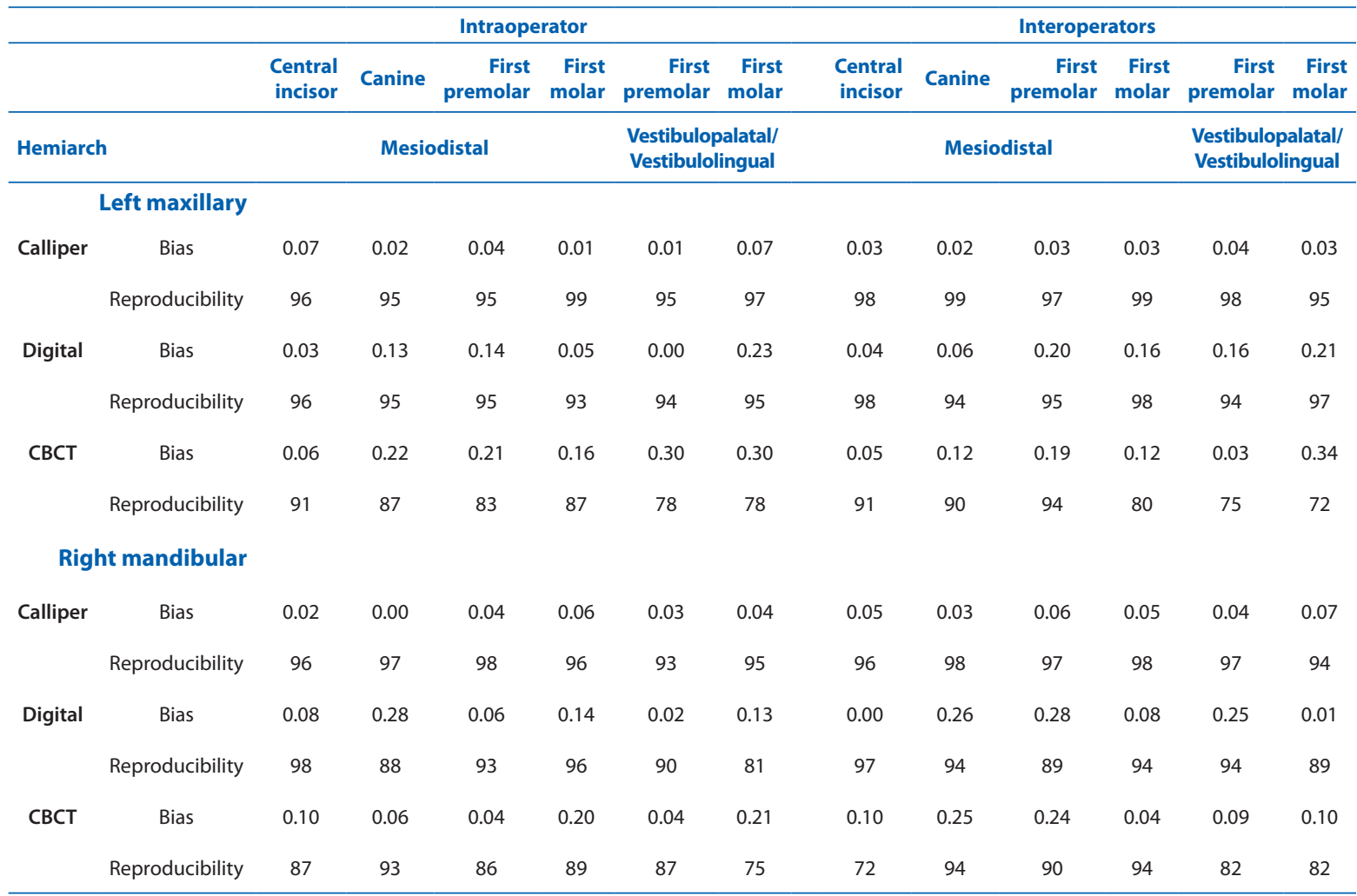

Bias values (absolute values) are in $\mathrm{mm}$, reproducibility coefficients are in $\%$

Table 2. Bland-Altman analysis for the three measurement methods.

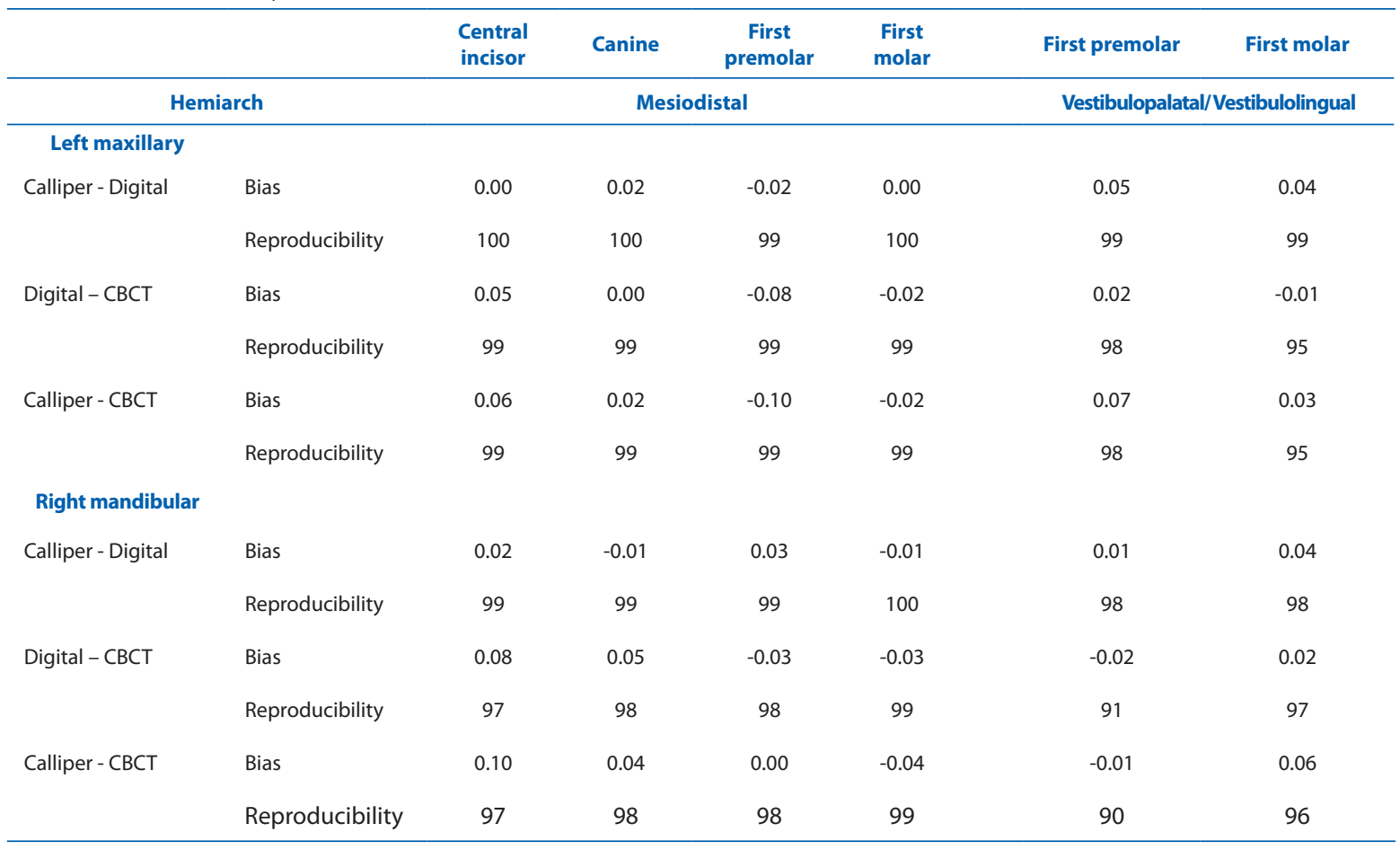

Bias values (absolute values) are in $\mathrm{mm}$, reproducibility coefficients are in \%

linear distances (crown dimensions) taken with three different techniques. Overall, differences among the measurements were limited, and their reproducibility very high, ranging between 90 and 100\%. Together with the comparison among methods, we investigated the variability inherent to each measurement protocol, namely the effect of repeated measurements made by the same and different operators. We found limited intra- and inter-operator variabilities. Indeed, the quantification of inter-operator reliability is necessary whenever multiple operators contribute to the analysis of the same dental reproductions. The good agreement between our two operators may be an effect of their prior calibration, which should be included in all measurement protocols [12].

Apparently, this is the first study that reported inter- 
operator differences: for instance, both White et al. [19] and El-Zanaty et al. [20] assessed only intra-examiner bias. Indeed, two or three different operators were involved in other studies, but only intra-operator variability was reported [6]. Similarly, Wiranto et al. [8] assessed the variability from three different operators, but did not report the actual inter-operator data, quoting a previous investigation.

The excellent reproducibility of the three different measurement techniques is in line with the current literature reports. For instance, De Luca Canto et al. [2] made an extensive review to study the validity of measurements obtained from digital dental models produced from laser scanning against those directly made on the original physical dental models. The authors concluded that the current scientific evidence supports the validity of digital measurements.

White et al. [19] tested the accuracy of the digital reproductions of dental models made by using CBCT scans, and found satisfactory values for intra-arch measurements but inaccurate inter-arch relationships. El-Zanaty et al. [20] compared linear distances obtained on plaster casts and from CT head scans; the two techniques had excellent agreement. More recent studies reported that both intraoral scanning and CBCT scanning of alginate impressions of the dental arches gave valid, reliable, and reproducible dental measurements for diagnostic purposes.

Wiranto et al. [8] compared traditional plaster scans, scans obtained from intraoral scans, and CBCT scans of alginate impressions, and found that the digital reproduction of dental arches can be usefully employed for diagnostic purposes.

In the current study, the worst coefficients of reproducibility were found for $C B C T$ measurements, while the best were those obtained for plaster casts. For CBCT, similar data were reported by Kim et al. $[4,5]$. Literature is not in agreement about the technique with the best reproducibility: both digital models $[4,5,7]$, and plaster models [16] had the best scores in different studies.

Overall, only three mesiodistal crown diameters had differences larger than $0.5 \mathrm{~mm}$, which is considered the threshold for clinical acceptability [7, 18]. This corresponds to $8 \%$ of the analysed dental distances (3 out of 12 distances $\times 3$ techniques values), a value larger than that reported by Tarazona-Álvarez et al. [6] who found only $5 \%$ of significant differences when comparing 20 linear distances obtained directly on dried mandibles and on their CBCT scans. Additionally, the current results well confirm that measurements involving the premolars are more variable than the other ones [4].

In general, the overestimation of calliper measurements vs. digital casts data is in line with the literature reports [18], while the comparison with CBCT data is more scattered. For instance, on dry mandibles, most of CBCT measurements were significantly smaller than those obtained by using the calliper [6].

\section{Conclusion}

In conclusion, measurements on digital dental models and $C B C T$ reconstructions of the dental arches seem clinically reliable as direct measurements performed on dental plaster casts. Inter- and intra-operator reliability
Table 3. $P$ values from Kruskal-Wallis test.

\begin{tabular}{|c|c|c|c|c|c|c|}
\hline & $\begin{array}{l}\text { Central } \\
\text { incisor }\end{array}$ & Canine & $\begin{array}{c}\text { First } \\
\text { premolar }\end{array}$ & $\begin{array}{c}\text { First } \\
\text { molar }\end{array}$ & $\begin{array}{c}\text { First } \\
\text { premolar }\end{array}$ & $\begin{array}{c}\text { First } \\
\text { molar }\end{array}$ \\
\hline Hemiarch & \multicolumn{4}{|c|}{ Mesiodistal } & \multicolumn{2}{|c|}{ Vestibulopalatal } \\
\hline $\begin{array}{l}\text { Left } \\
\text { maxillary }\end{array}$ & 0.09 & 0.93 & $0.002^{*}$ & 0.93 & 0.18 & 0.47 \\
\hline $\begin{array}{l}\text { Right } \\
\text { mandibular }\end{array}$ & 0.05 & 0.55 & 0.86 & 0.36 & 0.93 & 0.44 \\
\hline
\end{tabular}

*Significant difference $p<0.01$. For significant values, post hoc Wilcoxon tests: Calliper-CBCT: $p=0.002$; Digital - CBCT: $p=0.03$.

were acceptable, while more care may be needed for CBCT measurements, as also underlined by previous studies $[3,4]$.

The results are promising, nevertheless further evaluations on a larger sample are advised.

\section{Author Contributions}

LP: design of the study, data collection and interpretation, drafting the MS, final approval of the MS; MC: design of the study, data elaboration, drafting the MS, final approval of the MS; SG: data collection, critical review of the MS, final approval of the MS; FMER: data collection and elaboration, critical review of the MS, final approval of the MS; GMT: design of the study, data elaboration and interpretation, critical review of the MS, final approval of the MS; VP: design of the study, data collection, drafting the MS, final approval of the MS; CS: design of the study, data interpretation, critical review of the MS, final approval of the MS.

\section{Acknowledgments}

Not applicable. The study was self-funded. There are no conflicts of interest and no financial interests to be disclosed.

\section{References}

1. Codari M, Pucciarelli V, Pisoni L, et al. Laser scanner compared with stereophotogrammetry for measurements of area on nasal plaster casts. Br J Oral Maxillofac Surg. 2015;53(8):769-770. doi: 10.1016/j.bjoms.2015.05.007.

[Full text links] [PubMed] Google Scholar(4) Scopus(1)

2. De Luca Canto G, Pachêco-Pereira C, Lagravere MO, et al. Intraarch dimensional measurement validity of laser-scanned digital dental models compared with the original plaster models: a systematic review. Orthod Craniofac Res. 2015;18(2):65-76. doi: 10.1111/ocr.12068.

[Full text links] [PubMed] Google Scholar(13) Scopus(4)

3. Kau CH, Littlefield J, Rainy N, et al. Evaluation of CBCT digital models and traditional models using the Little's Index. Angle Orthod. 2010;80(3):435-439. doi: 10.2319/083109-491.1. [Full text links] [PubMed] Google Scholar(78) Scopus(41)

4. Kim J, Heo G, Lagravère MO. Accuracy of laser-scanned models compared to plaster models and cone-beam computed tomography. Angle Orthod. 2014;84(3):443-450. doi: 10.2319/051213-365.1.

[Full text links] [PubMed] Google Scholar(37) Scopus(16)

5. Kim J, Lagravére MO. Accuracy of Bolton analysis measured in laser scanned digital models compared with plaster models (gold standard) and cone-beam computer tomography images. Korean J Orthod. 2016;46(1):13-19. doi: 10.4041/ kjod.2016.46.1.13.

[Full text links] [Free PMC Article] [PubMed] Google Scholar(9) Scopus(6)

6. Tarazona-Álvarez P, Romero-Millán J, Peñarrocha-Oltra D, et al. Comparative study of mandibular linear measurements obtained by cone beam computed tomography and digital calipers. J Clin Exp Dent. 2014;6(3):e271-274. doi: 10.4317/jced.51426. [Full text links] [Free PMC Article] [PubMed] Google Scholar(11) Scopus(5)

7. Wan Hassan WN, Othman SA, Chan CS, et al. Assessing agreement in measurements of orthodontic study models: 
Digital caliper on plaster models vs 3-dimensional software on models scanned by structured-light scanner. Am J Orthod Dentofacial Orthop. 2016;150(5):886-895. doi:10.1016/j. ajodo.2016.04.021

[Full text links] [PubMed] Google Scholar(2) Scopus(1)

8. Wiranto MG, Engelbrecht WP Tutein Nolthenius HE, et al. Validity, reliability, and reproducibility of linear measurements on digital models obtained from intraoral and cone-beam computed tomography scans of alginate impressions. Am J Orthod Dentofacial Orthop. 2013;143(1):140-147. doi: 10.1016/j. ajodo.2012.06.018.

[Full text links] [PubMed] Google Scholar(96) Scopus(49)

9. Gibelli DM, Pucciarelli V, Pisoni L, et al. Quantification of dental movements in orthodontic follow-up: a novel approach based on registration of 3D models of dental casts. Stoma Edu J. 2017:4(1):55-61. doi: 10.25241/stomaeduj.2017.4(1).art.5.

10. Asgary S, Nikneshan S, Akbarzadeh-Bagheban A, et al. Evaluation of diagnostic accuracy and dimensional measurements by using CBCT in mandibular first molars. J Clin Exp Dent. 2016;8(1):e1-8. doi: 10.4317/jced.52570. [Full text links] [Free PMC Article] [PubMed] Google Scholar(1) Scopus(1)

11. Codari M, Pucciarelli V, Tommasi DG, et al. Validation of a technique for integration of a digital dental model into stereophotogrammetric images of the face using conebeam computed tomographic data. Br J Oral Maxillofac Surg. 2016;54(5):584-586. doi: 10.1016/j.bjoms.2016.01.019. [Full text links] [PubMed] Google Scholar(2) Scopus(0)

12. CodariM CaffiniM Tartaglia GM etal. Computer-aided cephalometric landmark annotation for CBCT data. Int J Comput Assist Radiol Surg. 2017;12:113-121. doi: 10.1007/s11548-016-1453-9. [Full text links] [PubMed] Google Scholar(2) Scopus(1)

13. De Angelis D, Gibelli D, Gaudio D, et al. Sexual dimorphism of canine volume: a pilot study. Leg Med (Tokyo). 2015;17(3):163146. doi:10.1016/j.legalmed.2014.12.006 [PubMed] Google Scholar(13) Scopus(5)
14. Horner K, Jacobs R, Schulze R. Dental CBCT equipment and performance issues. Radiat Prot Dosimetry. 2013;153(2):212-218. [Full text links] [PubMed] Google Scholar(26) Scopus(12)

15. Shaheen $E$, Politis $C$. The use of $3 D$ virtual planning and 3D printing for the treatment of facial asymmetry: a case report. Stoma Edu J. 2016;3(3-4):156-161. doi: 10.25241/ stomaeduj.2016.3(3-4).art.4.

16. Berco M, Rigali PH Jr, Miner RM, et al. Accuracy and reliability of linear cephalometric measurements from cone-beam computed tomography scans of a dry human skull. Am J Orthod Dentofacial Orthop. 2009;136:17e1-e9; discussion 17-18. doi: 10.1016/j.ajodo.2008.08.021

[Full text links] [PubMed] Google Scholar(200) Scopus(87)

17. Periago DR, Scarfe WC, Moshiri M, et al. Linear accuracy and reliability of cone beam $C T$ derived 3-dimensiona images constructed using an orthodontic volumetric rendering program. Angle Orthod. 2008;78(3):387-395. doi: 10.2319/122106-52.1.

[Full text links] [PubMed] Google Scholar(322) Scopus(159)

18. Radeke J, von der Wense C, Lapatki BG. Comparison of orthodontic measurements on dental plaster casts and 3D scans. J Orofac Orthop. 2014;75(4):264-274. doi:10.1007/s00056-014-0217-9. [Full text links] [PubMed] Google Scholar(14) Scopus(6)

19. White AJ, Fallis DW, Vandewalle KS. Analysis of intra-arch and interarch measurements from digital models with 2 impression materials and a modeling process based on cone-beam computed tomography. Am J Orthod Dentofacial Orthop. 2010;137(4):456.e1-9; discussion 456-457. doi: 10.1016/j. ajodo.2009.09.019.

[Full text links] [PubMed] Google Scholar(55) Scopus(27)

20. El-Zanaty HM, El-Beialy AR, Abou El-Ezz AM, et al. Threedimensional dental measurements: An alternative to plaster models. Am J Orthod Dentofacial Orthop. 2010;137(2):259-265. doi: 10.1016/j.ajodo.2008.04.030.

[Full text links] [PubMed] Google Scholar(71) Scopus(30)

\section{LUCa PISONI \\ DDS, PhD \\ LAFAS, Laboratory of Functional Anatomy of the Stomatognathic System Department of Biomedical Sciences for Health, University of Milan Milano, Italy}

Luca Pisoni, DDS, PhD, is currently a member of the research staff in the Laboratory of Functional Anatomy of the Stomatognathic System - LAFAS, Department of Biomedical Sciences for Health at the University of Milan, Milan, Italy. His fields of research are the morphological and metrical assessment of anatomical characteristics of craniofacial structures, dental arches, and teeth, including their modifications with age, sex and pathology. He authored/co-authored some papers published in international, peer reviewed Journals. He is also in private practice in Legnano (Milan, Italy).

\section{Which instruments can be used to obtain a 3D virtual model of dental arches?}

口a. Bite wing radiographs;

ab. Ultrasounds;

ac. Laser scans;

ad. Conventional orthopantomographs.

\section{Which instruments can be used to obtain a 3D virtual model of dental roots?}

口a. Laser scans;

b. Cone Beam Computerized Tomography (CBCT);

口. Teleradiographs;

ad. Surface EMG.

\section{In the current study we assessed}

$\square$ a. Three different methods to measure dental diameters:

bb. The effect of operator experience in making dental measurements;

ac. The use of Magnetic Resonance to measure dental diameters;

$\square$ d. Dental arch diameters in fully edentulous patients.

\section{In the current study, we found that}

$\square$ a. Intra-operator error was larger than 20\%;

ab. Measurements on the ultrasound reconstructions of the dental arches were clinically useful;

ac. Measurements on the laser scanned reconstructions of the dental arches were too prone to error;

$\square$ d. Measurements on the CBCT reconstructions of the dental arches were clinically reliable. 